\title{
Transmural Migration of a Retained Sponge Through the Rectum: A Case Report
}

\author{
Orhan Veli Özkan1', Gürhan Baş², Adem Akçakaya², Mustafa Şahin² \\ ${ }^{1}$ Department of General Surgery, Faculty of Medicine, Mustafa Kemal University, Hatay, Turkey \\ ${ }^{2}$ Department of $1^{\text {st }}$ General Surgery, Vakıf Gureba Training and Research Hospital, İstanbul, Turkey
}

\begin{abstract}
Retained surgical sponge in the abdomen following abdominal and pelvic surgery is an uncommon condition. Here we present a case of retained surgical sponge with unusual presenting symptoms. A 27 -year old female patient presented to our department with a foreign body localized in the anal region. She had a past history of a myomectomy 1 year earlier. Clinical examination and radiographic workout revealaed a sponge migrating towards the rectum. The sponge was removed under visual guidance of rectoscopy without laparotomy. The patient was discharged without complications.
\end{abstract}

Key Words: Gossypiboma, transmural migration, expulsion per rectum

Received: 02.01.2009

Accepted: 21.01.2009

\section{Introduction}

Gossypiboma (GP), is used to describe a mass in the abdomen which occurs as a result of a retained foreign object such as operative sponges or abdominal compresses made of cotton which exhibit no radioopacity. Textiloma or cottonoid terms are used to refer to the same event (1). Since the cases have certain medico-legal implications for the hospital and the surgeon, the true number of gossypiboma cases are believed to be greater than reported $(2,3)$. Reaching a diagnosis could be difficult due to vague nonspecific clinical symptoms and diverse imaging characteristics such as ileus and abscess. Plain abdominal radiograph, ultrasonography (USG), computed tomography (CT), and magnetic resonance imaging (MRI) help in establishing the diagnosis.

Here, we presented a case of retained sponge migrating towards the rectum after myomectomy.

\section{Case Report}

A 27-year-old female patient presented with abdominal pain and diarrhea for 6 months. She had recently experienced a foreign object protruding through the anus. Her medical history revealed that she had undergone myomectomy through laparotomy 1 year previously. The patient also reported that she had no complaints in the first 6 months. Her physical examination was normal for except vague pain in the right lower quadrant of the abdomen and cotton fibers in the rectal examination. Biochemical analyses, complete blood count, and plain abdominal radiograph showed no pathology. USG displayed a mass lesion with echogenic foci, localized in the right ovarian portion which could not be discerned clearly from the rectum. The right ovary exhibited an expanded view (Figure 1). CT revealed a component of textiloma protruding into the lumen of the rectum (Figure 2). Under rectoscopy, a sponge partially located in the rectum was detected. It was removed without encountering any resistance. The patient had no complication later and was discharged after 7 days.

\section{Discussion}

Gossypiboma is a term used for describing the mass formed as a result of the entrapment of a cotton object within the abdomen. While this term is usually preferred by AngloSaxon authors, European investigators generally use the word textiloma. Determining the true incidence of GP is not easy, because some cases follow an asymptomatic course and do not exhibit their first symptoms for years. Therefore, its incidence is reported to vary between $1 / 1000$ and $1 / 1500(1,4,5)$. In the USA, the incidence of retained objects is estimated to be 1500 per year (6). Despite the use of radiopaque materials and meticulous efforts in counting during the operation, the cases of retained objects continue to occur. However, strict follow-up of the patient safety rules can help to reduce the incidence.

Several reports identified the risk factors for abdominal retained sponge cases: emergency operation, being forced to perform unexpected surgical procedures, poor organization, hasty sponge count, long duration of operation, unstable patient, operations conducted by assistants, and obesity $(2,6)$.

There may be various presenting symptoms of GP. It may cause distension, ileus, pain, tenesmus, palpable mass, vomiting, weight loss, diarrhea, abscess, and fistula (1). In the pres- 


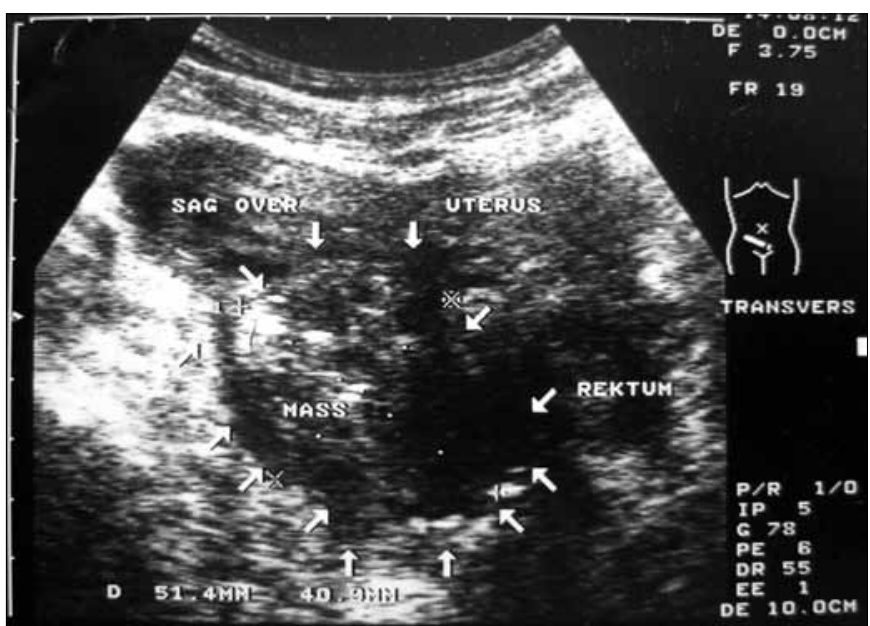

Figure 1. USG Displaying a Mass Lesion

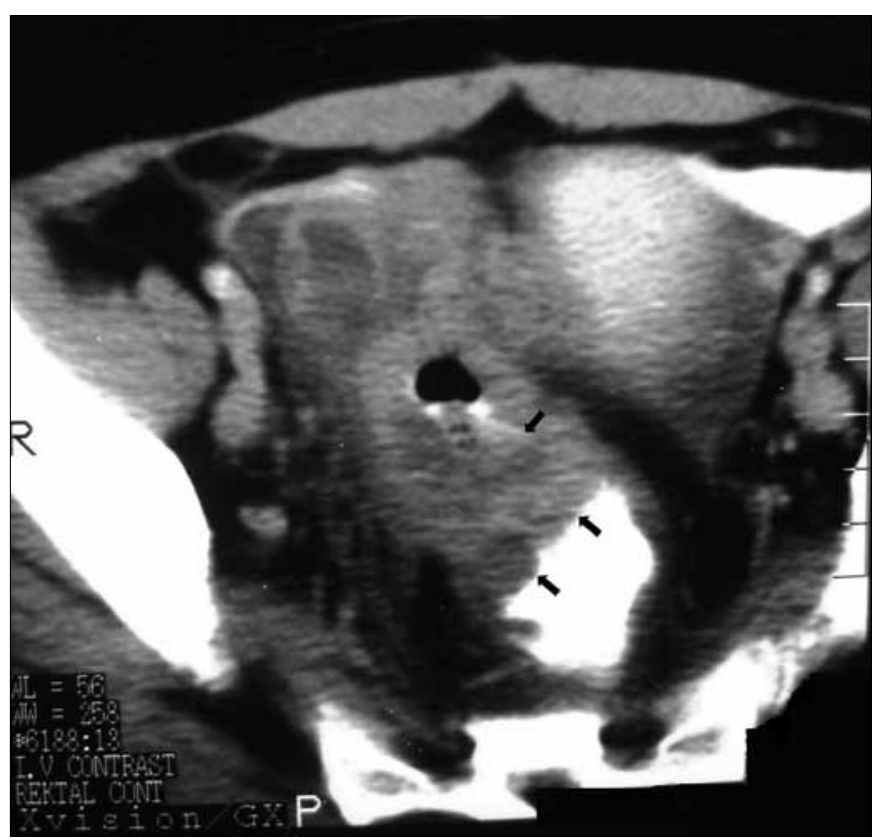

Figure 2. CT Showing Gossypiboma Protruding Into the Rectum (Arrowheads)

ent case, it had caused abdominal pain and diarrhea followed by protrusion of the foreign object from the rectum.

Without a radiopaque marker on the sponge, it is difficult to establish a radiologic diagnosis. Radiologic diagnostic modalities such as USG, CT, and MRI prove to be useful in diagnosis. CT images could show a structure including cystic lesions, air bubbles, hyperdense capsula, and spotted calcifications in GP $(7,8)$. However, it must be noted that it may mimic a malignant mass (9) in chronic cases. In the present case, plain radiograph was of no value, since the sponge was not radioopaque. USG displayed equivocal findings with a mass lesion, localized in the right ovary which could not be discerned from the rectum. However, CT showed the foreign object advancing towards the rectum within the rectal lumen.
Sponge causes 2 types of reactions in the body $(3,10)$ First, it can form an aseptic tissue surrounding itself and generate an encapsulated granuloma or pseudotumor. The second reaction is that it can lead to formation of a capsula, and chronic or external fistula. While septic complications arise in the early postoperative period, GP development can last for years. Moreover, a sponge retained in the abdomen may lead to perforation of intestines or other organs, obstruction, sepsis and even death. Migration to the intestines can cause partial or complete obstruction and bleeding through erosion of the mucosa, and migration to bladder may result in urinary problems. After migration through the intestines, the sponge can be expelled per rectum spontaneously as a result of the peristaltic movement $(1,11,12)$ In the present case, the object was observed to have migrated to rectum in 1 year after the operation.

Having diagnosed GP, the foreign object should be removed endoscopically or by surgery. In the present case, sponge had already migrated to the rectum and it was removed by rectoscopy with minimal intervention.

In conclusion, the possibility of GP should always be kept in mind in patients with an inunusual presentation and a recent history of operation.

\section{Conflict of Interest}

No conflict of interest was declared by the authors.

\section{References}

1. Zantvoord Y, van der Weiden RM, van Hooff MH. Transmural migration of retained surgical sponges: a systematic review. Obstet Gynecol Surv 2008;63:465-71. [CrossRef]

2. Sarda AK, Pandey D, Neogi S, Dhir U. Postoperative complications due to a retained surgical sponge. Singapore Med J 2007;48:160-4.

3. Bani-Hani KE, Gharaibeh KA, Yaghan RJ. Retained surgical sponges (gossypiboma). Asian J Surg 2005;28:109-15. [CrossRef]

4. Rappaport W, Haynes K. The retained surgical sponge following intra-abdominal surgery. A continuing problem. Arch Surg 1990;125:405-7.

5. Ahmad G, Attiq-ur-Rehman S, Anjum MZ. Retained sponge after abdominal surgery. J Coll Physicians Surg Pak 2003;13:640-3.

6. Gawande AA, Studdert DM, Orav EJ, Brennan TA, Zinner MJ. Risk factors for retained instruments and sponges after surgery. N Engl J Med 2003;348:229-35. [CrossRef]

7. A Malik, Jagmohan P. Gossypiboma : US and CT appearance. Ind J Radiol Imag 2002;2:503-4.

8. Yeung KW, Chang MS, Huang JF. Imaging of transmural migration of a retained surgical sponge: a case report. Kaohsiung $J$ Med Sci 2004;20:567-71. [CrossRef]

9. Yamamura N, Nakajima K, Takahashi T, Uemura M, Nishitani A, Souma $Y$ et al. Intra-abdominal textiloma. A retained surgical sponge mimicking a gastric gastrointestinal stromal tumor: Report of a case. Surg Today 2008;38:552-4. [CrossRef]

10. Prasad S, Krishnan A, Limdi J, Patankar T. Imaging features of gossypiboma: report of two cases. J Postgrad Med 1999;45:18-9.

11. Godara R, Marwah S, Karwasra RK, Goel R, Sen J, Singh R. Spontaneous transmural migration of surgical sponges. Asian J Surg 2006;29:44-5. [CrossRef]

12. Choi JW, Lee $\mathrm{CH}$, Kim KA, Park CM, Kim JY. Transmural migration of surgical sponge evacuated by defecation: mimicking an intraperitoneal gossypiboma. Korean J Radiol 2006;7:212-4. [CrossRef] 